\title{
SHOOTING ANALYSIS OF LITHUANIAN NATIONAL BASKETBALL MEN'S TEAMS IN DIFFERENT AGE CATEGORIES
}

\author{
Lukas Danilevičius, Rasa Kreivytė \\ Lithuanian Sports University, Kaunas, Lithuania
}

\begin{abstract}
Background. One of the most important problems for players, coaches and scientists is improving the accuracy of shooting the basket. It is the most important technique for playing basketball, and its dependence on performance is multifaceted.

Methods. All 37 games in the 2015 European Championships in U16, U18, U20 and men's national team were analyzed. Data was selected from the official boxscores of FIBA (International Basketball Federation). The following absolute game-related statistics were gathered: free-throws, 2-point and 3-point field goals (both successful and unsuccessful). The obtained values of the rate of success of 2-point, 3-point and free throw shooting were tested by the non-parametric Mann-Whitney $U$-test. The statistical analyses were performed using SPSS for Windows, version 20.0 , and statistical significance was set at $p<.05$.

Results. Comparing the number and accuracy of shots taken from 2-point distance, we found that there was no significant difference between men of different ages $(p>.05)$. Most 3-point shots were done by U16 youth team, the least was in men's national basketball team, a significant difference in the indicators $(p<.05)$ was found between all the teams, except between men's national team and U18 $(p>.05)$. Comparing free-throws' indicators between different age groups, most throws were done by U16 team, the least were done by the U20 team $(p<.05)$; however, there were no differences between the other significant indicators $(p>.05)$. Comparing free-throws accuracy indicators between the different age groups of basketball teams, significant differences in indicators were found between men's national basketball team and $\mathrm{U} 20, \mathrm{U} 16(p<.05)$.

Conclusions. The count of 2-point shots made in Lithuanian different age basketball national team games was more or less similar. Most 3-point shots were made by U16 team and the national men's team made least 3-pointers. The indicators of accuracy did not have a significant difference between national teams, except for free throws: men's national team made these shots most accurately, opposite situation was with U16 team.
\end{abstract}

Keywords: basketball, national teams, shooting, quantitative and qualitative indicators.

\section{INTRODUCTION}

$\mathrm{O}$ ne of the most important areas of sports science research is the research of the variables of the competition activity (game), the change of their characteristics in the most important competitions (O'Donoghue, 2010). Recording and evaluating player readiness and performance indicators is the fundamental function of the management of basketball players' sports training (Malarranha, Figueira, Leite, \& Sampaio, 2013). The analysis of the performance indicators of the Worlds and Europe best basketball teams provides a lot of objective information about the basketball game, its development and the results achieved (Kreivyte et al., 2013). It is possible to evaluate the team game, its change by analysing the quantitative (rebounds, shooting into basket from different distances, free throws, etc.) and qualitative (accuracy of shooting) indicators (Csataljay, James, Hughes, \& Dancs, 2012). One of the most important problems for players, coaches 
and scientists is improving the accuracy of shooting the basket (Erčulj \& Štrumbelj, 2015; Gómez, Alarcón, \& Ortega, 2015; Ibanez, Santos, \& Garcia, 2015). Basketball is the most important technique for playing basketball, and its dependence on performance is multifaceted (Skinner, 2012).

While playing, the accuracy of the shoots is determined by the biomechanical parameters of the action (Ammar, Chtourou, Abdelkarim, Parish, \& Hoekelmann, 2015), and the stability of the movements (Uygur, Gottepe, Ak, Karabörk, \& Korkusuz, 2010), the ability of the body to adapt to various intensity and nature physical loads (Montgomery, Pyne, \& Minahan, 2010), and player psychics (Mellalieu, Neil, Hanton, \& Fletcher, 2009). The turn of shooting the ball indicators during the match is influenced by active rival defence actions, the defence system, the physical and mental state of the players, depending on the importance of the match and their result. In addition, it is especially important from what distance from which place of the court is and how it is shot (Gómez et al., 2015).

The turn of the shooting the basket indicators during the match is influenced by active rival defence actions, applied defence systems, physical and mental state of the players, depending on the importance of the match and the result. In addition, it is especially important from what distance from which court place and how it is shot (Gómez et al., 2015). Lithuanian national men's basketball team and youth teams of different age at the European championships show very high results, so it would be important to set quantitative and qualitative indicators for basketball shootings (2-point and 3-point field-goal and free-throw percentages) and their differences between teams in different age categories.

Hypothesis. The accuracy of men's basketball shooting is improving with age. This assumption is based on monitoring the evolution of male development.

The aim of this study was to determine and evaluate quantitative and qualitative indicators of basketball shots of different age groups of Lithuanian national basketball teams.

\section{METHODS}

Sample and variables. All 37 games in the 2015 European Championships in U16 (9 games), U18 (9 games), U20 (10 games) and men's national team (9 games) were analyzed. Data was selected from the official boxscores of FIBA (International Basketball Federation). The following absolute game-related statistics were gathered: free-throws, 2-point and 3-point field goals (both successful and unsuccessful).

Statistics analysis. From the primary data on the absolute number of shots and successful throws we calculated the percentage rate of success of the observed shooting in the given men's age category. Percentage values of the rate of success of 2-point, 3 -point and free throw shooting and the level of statistical significance were expressed in the form of a graph. In the course of the whole research we also used alternative methods of logic. The obtained values of the rate of success of 2-point, 3-point and free throw shooting were tested by the nonparametric Mann-Whitney $U$-test. The statistical analyses were performed using SPSS for Windows, version 20.0 (SPSS Inc., Chicago IL), and statistical significance was set at $p<.05$.

\section{RESULTS}

Lithuanian national men's basketball team attempted around $40.9 \pm 8.0$ shots from 2-point distances during one European championship game, U20 team attempted $38.4 \pm 7.4$ throws, U18 team attempted $44.6 \pm 9.3$ throws and U16 team attempted $40.6 \pm 6.7$ throws. The most 2-point shootings were done by the U18 team and the least was by the U20 team, however there was no difference between all the significant variables ( $p>$ .05) (Figure 1).

Accuracy indicators of 2-point throws: men's basketball team made throws at $44.8 \pm 11.3 \%$ accuracy, U20 youth team shooting accuracy indicator was $48.1 \pm 4.2 \%$, U18 team 2-point shots accuracy indicator was $44.2 \pm 7.1 \%$ and U16 team shooting accuracy was $48.5 \pm 6.7 \%$. Comparing the accuracy of shots taken from 2-point distance, it indicates that there was no significant difference between teams of different ages $(p>.05)$ (Figure 2).

Men's national basketball team during the European championship match averaged $16.7 \pm 4.3$ shots from 3-point distance, U20 team averaged $23.4 \pm 3.7$ shots, U18 team averaged $18.6 \pm 5.2$ shots, and U16 team averaged $28.2 \pm 6.2$ shots. Most 3 -point shots were performed by U16 youth team, the least was in men's national basketball team, a significant difference in the indicators $(p<.05)$ was found between all the teams, except between men's national team and U18 $(p>.05)$ (Figure 3). 

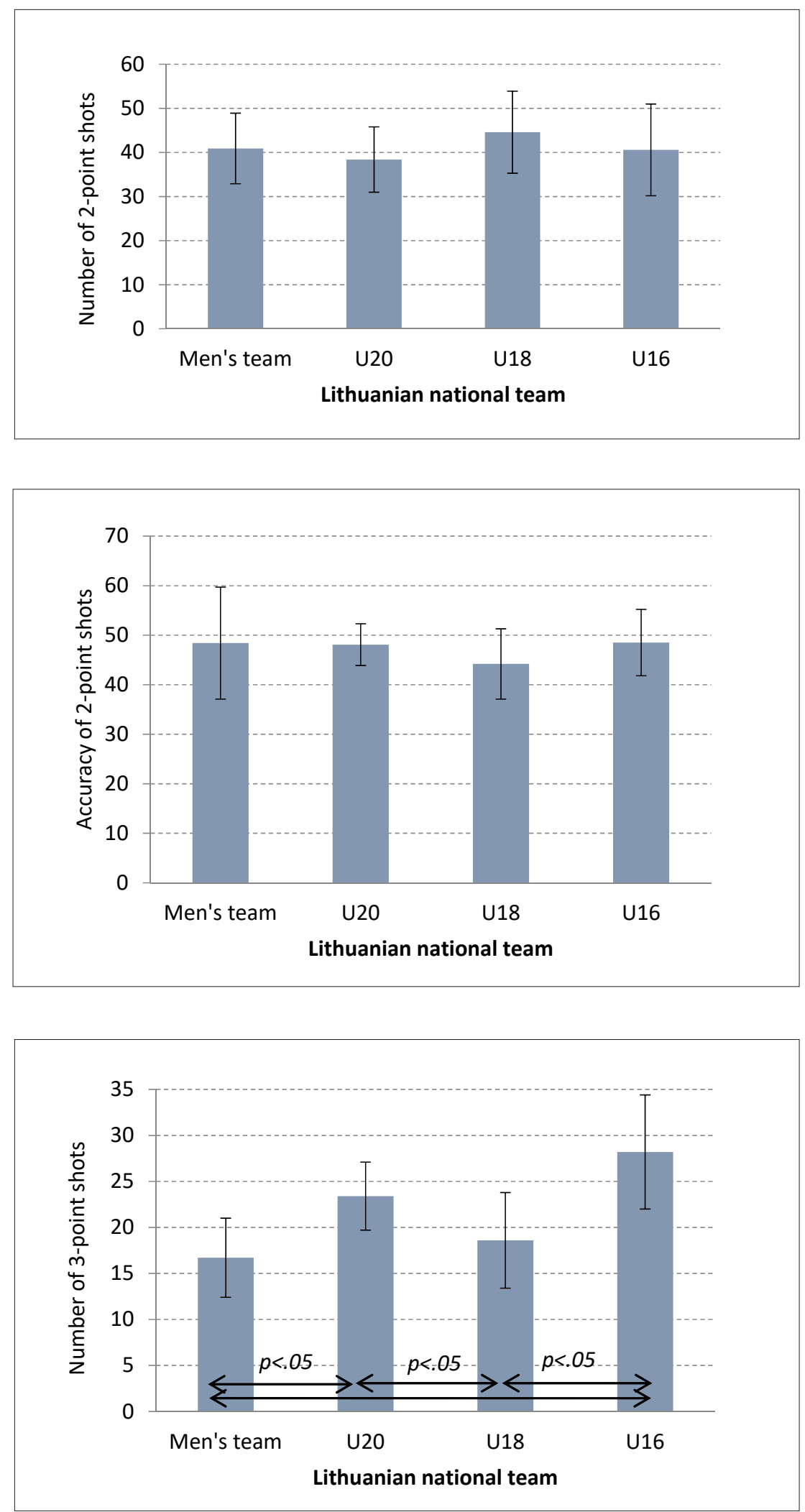

Figure 1. The number of 2-point shots for men's basketball teams in the European championship matches (average per one game)

Figure 2. The accuracy of 2-point shots for men's basketball teams in the European championship matches (average per one game)

Figure 3. The number of 3-point shots for men's basketball teams in the European championship matches (average per one game)
Accuracy indicators of 3-point throws: the men's basketball team from near and long range shots attempted $33.9 \pm 12.3 \%$ accuracy, U20 team throw accuracy indicators were $28.5 \pm 9.5 \%$, U18 team three-point shot accuracy indicators were $32.0 \pm$ $7.1 \%$ and U16 team shot accuracy were $32.7 \pm 9.4 \%$.
Comparing shots from long-range accuracy indicators between the different age groups of basketball teams, the best results from 3-point distance were showcased by the men's national basketball team, however, there were no significant differences between the variables $(p>.05)$ (Figure 4). 

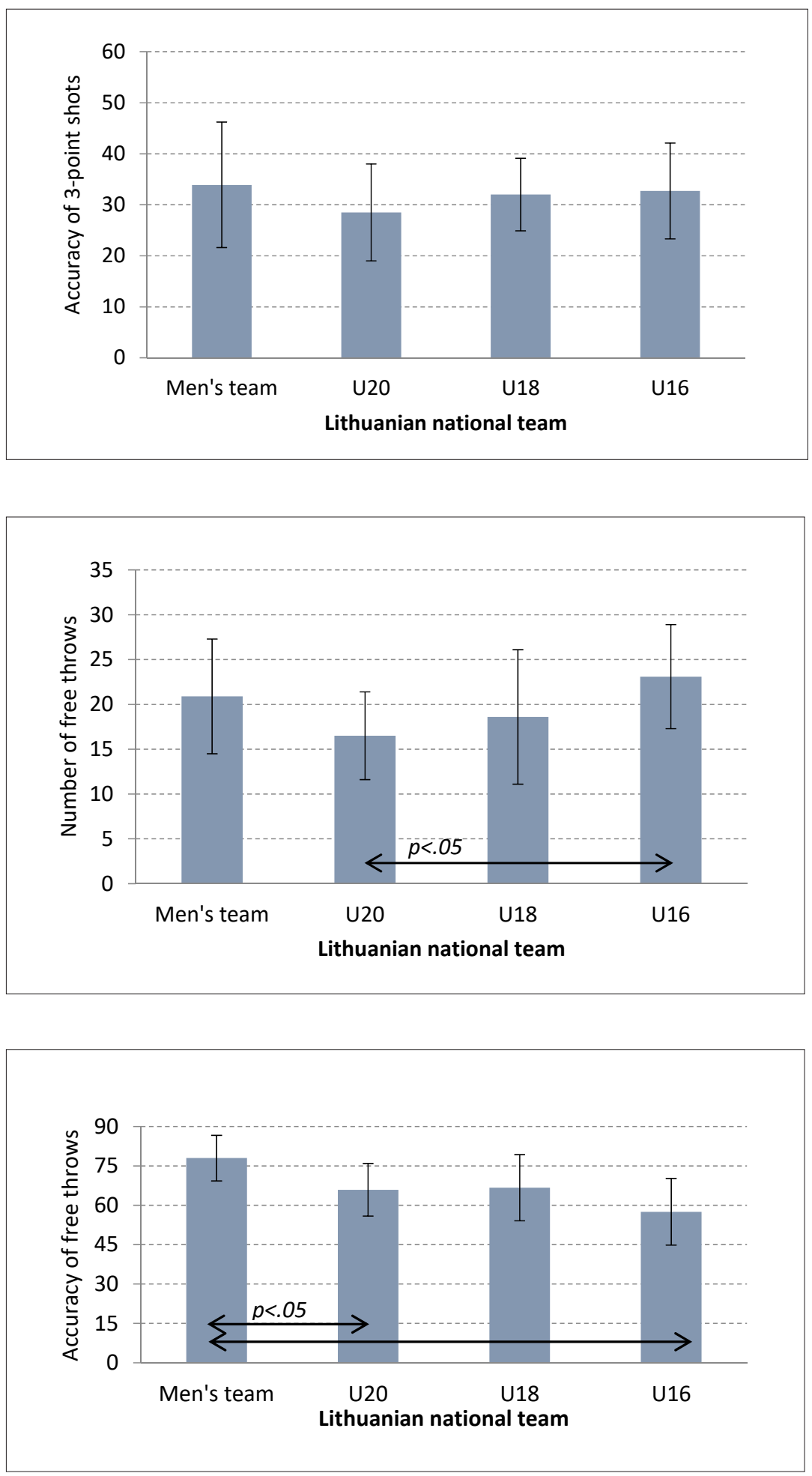

Figure 6. The accuracy of free throws for men's basketball teams in the European championship matches (average per one game) men's basketball teams in the European championship matches (average per one game) men's basketball teams in the European championship matches (average per one game)
Men's national basketball team attempted $20.9 \pm 6.4$ free throws per game, U20 team had $16.5 \pm 4.9$ free-throws, U18 team attempted $18.6 \pm$ 7.5 throws and U16 team had $23.1 \pm 5.8$ throws. Comparing free-throw indicators between different age groups, most throws were performed by U16 team, the least were done by the U20 team ( $p<$
$.05)$ however, there were no differences between the other significant indicators $(p>.05)$ (Figure 5).

Accuracy indicators of free-throws: men's national basketball team's attempted free-throws had accuracy of $78.0 \pm 8.7 \%$. U20 team free-throw accuracy indicators were $65.9 \pm 10.1 \%$, U18 team free-throw accuracy indicators were $66.7 \pm 12.6 \%$ 
and U16 team free-throw accuracy was $57.5 \pm$ $12.7 \%$. The best results from the free throws were showcased by the men's national basketball team. Comparing free-throw accuracy indicators between the different age groups of basketball teams, significant differences in indicators were found between men's national basketball team and U20, U16 $(p<.05)$. No significant difference was observed $(p>.05)$ between men's national basketball team and U18 team (Figure 6).

\section{DISCUSSION}

The main aim of this research was to compare the shooting indices of the Lithuanian national basketball men's teams in different age categories. During the professional games between men teams, the end of the match is determined by the total number of successful shots, especially from 2-point distances (these throws make up the major part of the final result). Our researched team's 2-point shots number in the games reached 41-44 throws. Decrease in number of these shots (by $8-10$ shots) has been observed in the last European championships (Kreivyte et al., 2013). Decrease of these throws might have been due to active defence practices in restricted area because of increased number of 3-point shots. Lithuanian different age group team shots' precision 2-point distance indicators were poor, accuracy ratio did not even reach $50 \%$. The best results for the best 2-point shots were achieved by men and U16 team whose accuracy stood at $48 \%$. Many authors (Csataljay et al., 2012; Skinner, 2012) developed an assumption that 2-point shots accuracy can often result in the end of the games. The number of successful shots from 2-point distances and accuracy are indicators of effective attacks, which proves that winning teams are tactically more disciplined, having clearer tasks. Oliver (2004) asserts that in a basketball team whose game pace is slower, 2-point distance shot accuracy is higher. The author assumes that team coaches are getting ready for the game and focusing on improving these throws as well as improving ball control. Our analysed team's 3-point shots during games are much higher compared to other national teams. The most 3-point distance shots are done by U16 team (on average 28 shots per game); the least 3-point distance shots are being done by men team (in average 17 shots per game). It has been established that losing teams at the end of the games are usually trying to save the result by conducting 3-point distance shots, therefore, in games where result is very tight, winning teams have less 3-point distance shots, but their accuracy is higher (Lorenzo et al., 2010; Gómez et al., 2015). The number of free-throws per game indicates team's activeness while organizing and executing attacks when opponent uses active defence systems (Csataljay et al., 2012). The accuracy of free-throws shows players' actions under the pressure of physical and psychological pressure, consistency, mental strength as well as reliability (Uygur et al., 2010). Lithuanian men's basketball team was not active in free-throws compared to European champion - the Spanish team, additionally, Lithuanian free-throws' accuracy was lower compared to the champions' team. It has been ascertained that the best player's free-throw precision ratio in the games was $76 \%$. Shot accuracy which reaches $90 \%$ and more is considered the best, whereas the ratio which reaches $65 \%$ is considered low (Vickers, 2007). Free-throw precision indicators in different youth age group (U16, U18, U20) teams were much lower compared to adult men's team. There was a hypothesis that the accuracy of the throws should improve with age, but the results only partially confirmed the hypothesis: the results of the U20 team's 3-point and fine throws were not better than those of the U18 team.

\section{CONCLUSIONS}

The count of 2-point shots made in Lithuanian different age basketball national team games was more or less similar. Most 3- point shots were made by U16 team and the national men's team made least 3-pointers. Comparing shots from the free throw line, the leaders were U16 team. U20 team rarely made free throws. The indicators of accuracy did not have a significant difference between national teams, except for free throws: men's national team made these shots most accurately, the opposite situation was in the U16 team. The accuracy of 2-point shots, 3-point shots (except for U18 team) and free throws between various age national teams was similar. 


\section{REFERENCES}

Ammar, A., Chtourou, H., Abdelkarim, O., Parish. A., \& Hoekelmann, A. (2015). Free throw shot in basketball: kinematic analysis of scored and missed shots during the learning process. Sport Sciences for Health, 12(1), 1-7. doi: $10.1007 / \mathrm{s} 11332-015-0250-0$

Csataljay, G., James, N., Hughes, M., \& Dancs, H. (2012). Performance differences between winning and losing basketball teams during close, balanced and unbalanced quarters. Journal of Human Sport \& Exercise, 7(2), 356364. doi: 10.4100/jhse.2012.72.02

Erčulj, F., \& Štrumbelj, E. (2015). Basketball shot types and shot success in different levels of competitive basketball. PLoS ONE, 10, e0128885. https://doi. org/10.1371/journal.pone.0128885

Gómez, M. A., Alarcón, F., Ortega, E. (2015). Analysis of shooting effectiveness in elite basketball according to match status. Revista de Psicologia del Deporte, 24(1), $37-41$.

Ibanez, S. J., Santos, J. A., \& Garcia, J. (2015). Multifactorial analysis of free throw shooting in eliminatory basketball games. International Journal of Performance Analysis in Sport, 15, 897-912. https://doi. org/10.1080/24748668.2015.11868839

Kreivyte, R., Emeljanovas, E., Sporiš, G., Knjaz, D., Vučkovič, G., \& Milanovič, Z. (2013). Shooting performance did not change in elite women's national basketball teams from 1995 to 2011. Annales Kinesiologiae, 4(1), 45-56.

Lorenzo, A., Gómez, M. A., Ortega, E., Ibánez, S., \& Sampaio, J. (2010). Game related statistics which discriminate between winning and losing under-16 male basketball games. Journal of Sport Science and Medicine, 9, 664-668.

Malarranha, B., Figueira, J., Leite, N., \& Sampaio, J. (2013). Dynamic modelling of performance in basketball. International Journal of Performance Analysis in Sport, 13, 377-386. https://doi.org/10.1080/24748668.2013.11 868655

Mellalieu, S. D., Neil, R., Hanton, S., \& Fletcher, D. (2009). Competition stress in sport performers: Stressors experienced in the competition environment. Journal of Sports Science, 27(7), 729-744. doi: 10.1080/02640410902889834

Montgomery, P. G., Pyne, D. B., \& Minahan, C. L. (2010). The physical and physiological demands of basketball training and competition. International Journal of Sports Physiology and Performance, 5(1), 75-86.

O’Donoghue, P. (2010). Research methods for sport performance analysis. New York: Routledge.

Oliver, D. (2004). Basketball on paper: Rules and tools for performance analysis. Dulles: Potomac Books.

Skinner, B. (2012). The problem of shot selection in basketball. PLOS ONE, 7, e30776. https://doi. org/10.1371/journal.pone.0030776

Uygur, M., Gottepe, A., Ak, E., Karabörk, H., \& Korkusuz, F. (2010). The effect of fatigue on the kinematics of free throw shooting in basketball. Journal of Human Kinetics, 24, 51-56. doi: 10.2478/v10078010-0019-0

Vickers, J. N. (2007). Perception, cognition, and decision training: The quiet eye in action. Human Kinetics. 